\title{
Design Considerations for Plasma Accelerators Driven by Lasers or Particle Beams
}

\author{
C. B. Schroeder, E. Esarey, C. Benedetti, Cs. Tóth, C. G. R. Geddes and W. P. \\ Leemans
}

Lawrence Berkeley Natronad Labos atory. Berketey, Calbou nta 94720, USA

\begin{abstract}
Absiraxt. Plasma accelerabrs may be drmen by the ponderomotuve force of an inlense laser or the spece-chage force of a charged paricke bean The impliçalions for acolerator design and the different physical mechanisms of laser driwels and beam-iniven plasma acceleration are discussed Driver propagation is examuned, as well as the effects of the excited plasiua wave phase veloctly The driver coupling to subsequent plasme acceleralor slages for bugh-enercy physict applicestons is addressed
\end{abstract}

PACS. $5238 \mathrm{Kd} 5240 \mathrm{MJ}$

\section{INTRODUCTION}

Plasma-based accelerators have atisacled considerable atlentwon owing to the ultrahigh field gradients susianable in a plasma wave, enablung compact accelerators These relatuvisuc plasmis waves may be excited by the nonlınear ponderomotive forse of an intense laser or the space-charge fotce of a charged patticle beam

Laser-driven plasma accelerators (LPA6) were first proposed in 1979 by Tajuma and Dawson [I] (For a recent review of laser-plasma acceleration, see Ref [2] ) Al the tıme that lases-plasma accelerators were proposed, the rechnology to produce interse $\left(\geq 10^{18} \mathrm{~W} / \mathrm{cm}^{2}\right.$ ), short-pulse (sub-ps, the duration of the plasma period) lasers did not exist, so beating two long laser pulses to produce the reguired lemporal structure was considerell ta e the plesma beat twave acceleralur [3]) Chrped pulse amplificalıon was developed in the mid-1980's [4], makıng sources of intense, high-power lasers avalable, and the field of laser-plasma acceleration has benefitted greatly from the rapid advances in compect high peok power laser technology over the lasi decade

The basic mechamism for acceleratıon by particle beam-diven plasma wayes was first analyzed by Chen $e$ al [5] In beam-druen plasma accelerators, or plasma wakefield accelerators (PWTA), the electron plasma wave (space-charge

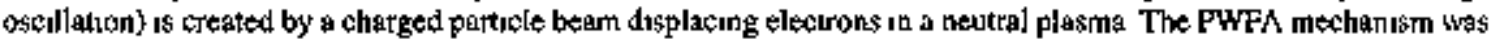
expenmentally demonstraled in the late 80's in a șet of experuments al ANI. [6], where a wilness bunch was de]ayed to map the plasma wave excited by a drive beam Bean-dnven plasma accelerators have benefitted greatly by recent improvements in linac technology that alow the production of high denslly beanis of ultrashort ( $<\rho g$ ) durations

There has been significant recent experimental suceseses using lasers and particle betum deivers for plasma acceleration In partculas, for LPAs, the demonstration ai LBNL in 2006 of high rquality, 1 GeV electron beams produced In approximately $3 \mathrm{~cm}$ plasms using a $40 \mathrm{TW}$ laser [?] In 2007 , for PWHAs, the energy doub] ıng aver a meter to $42 \mathrm{GeV}$ of a fraction of beam electrons on the tail of an electron beam by the plasina wave excited by the head was demonsirated at SLAC [8] These expenmental successes haye resulted in furcer interest in the dewelopment of plasma-based acceleratıơn as a basis for a linear collider, and prelımunary collider designs using laset-drivers [9, 10 ] and beam deivers [II] are being deweloptod

I.aser-driyer excitation of plasma waves uses the nonlunear ponderomoitue force (radiabon pressure) of an untense laser Beam-dnven plasma waves are excited by the space-charge force of a dense charged-particle beam These two different physical mechanisms of plastha wave excitation, as well as the typical characteristucs of the dnvers, have implications for accelerator design In this proceedings paptr, we discuss the simulanties and differences bel ween waye exctation by lasers and particle beams In the following, field sliucture of the plasma wave driven by lasers or parlicle beams is discussed, as well as the regimes of operation (linear and nonlunear) and the operational plesma density for the plasma acceleravor Dnver propagalion us discussed, as is driver coupling to subsecquent plasma acteclerator shages 


\section{PLASMA WAVE EXCITATION}

Although large amplitude, relatıvistic plasma wayes can be driven enther by electron beams or laser pulses, the phystcal forces that drive the wave are different Consider the eleciron plasina density perturbatron excited by a laser or beam dnver Combining the plasmk flud momentum equation, plasma contınuly equation, sind Gauss's law, in the lonear regime, the eleciros plasma density perturbation in als intitally un Iform plasma takes the torm of a driven hattmonic oscillation

$$
\left(\frac{\partial^{2}}{\partial t^{2}}+\omega_{\nu}^{2}\right) \frac{n}{m_{b}}=-\omega_{p}^{2} \frac{m_{b}}{s_{0}}+c^{2} \nabla^{2} \frac{\theta^{2}}{2},
$$

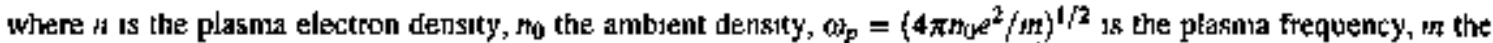
election mass, $-\varepsilon$ the electron charge, $\pi_{b}$ is the team density, and $a=e A / m c^{2}$ is the normalized yector polentsal of the laser The drive term lon the nght hand side of $\mathrm{Eq}$ (1)] can elther be an electron beam or a laser pulse As seen from Eq ( () there are some common features of beam driven and laser-driven excitation For example, the accelerating bucket size is given by the plasma wavelength $\lambda_{p}=2 \pi c / \omega_{p}$. The wave excitation is most afficien for druyer durations less than, of on the order of, the plasma penod The phase velocity of the wave is determined by the driver velocity And the characteristıc accejeraling field for large denssty perturbations ( $n \sim n_{0}$ ) is or the order of the cold nonrelativistuc wavebreaking field $E \sim E_{D}=m c \omega_{p} / z$ For ex\&mpie, a plasma density of $10^{18} \mathrm{cmn}^{3}$, y]elds $\lambda_{p} \simeq 33 \mathrm{dm}$ and $E_{0} \simeq 96 \mathrm{GVIm}$, this field is appropsately three orders of magnitude greater than that obianed in conventronal linacs

Although, from Eq (1), excltatuon of the plasma densily perturbation from enther beam or laser dyvers appeers

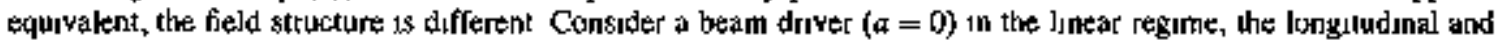
transverse fields arc, assuming eylindreal symmetry and a highly relatıyıstic drı re beam, [12]

$$
\begin{aligned}
& E_{\mathrm{z}} / E_{0}=-k_{p}^{3} \int d \zeta_{p}^{\prime} \int r^{\prime} d r^{\prime} \cos \left[k_{p}\left(\zeta-\zeta^{\prime}\right)\right] k_{0}\left(k_{p} r_{c}\right) K_{0}\left(k_{\rho^{\prime}}{ }_{3}\right) \pi_{b}\left(r^{\prime}, \zeta^{\prime}\right) / n_{0:} \\
& \left(E_{\mathrm{r}}-B_{\theta}\right) / E_{0}=-k_{p}^{2} \int d \zeta^{r} \int r^{s} d r^{\prime} \sin \left[k_{p}\left(\zeta-\zeta^{\prime}\right)\right] f_{1}\left(k_{p} r_{<}\right) K_{1}\left(k_{p} r_{>}\right) \partial_{1}+H_{b}\left(r^{\prime}, \zeta^{\prime}\right) / N_{0},
\end{aligned}
$$

where $\zeta=z-c t$ is the co-moving wariable, $s,(r)$ are the smaller (lerget) of $r$ and $r^{r}$, and $I_{\mathrm{m}}$ and $K_{\mathrm{m}}$ are modified Bessel funcions of the $\mathrm{m}^{\text {th }}$ Xund Equations (2) and (3) indicate that the rad1a] extent of the beam-dnven wakefields is grven by the larger of the plasma skin depih $k_{p}{ }^{\prime}$ and the bean raduus For narrow bunches $\left(k_{p} t_{b} \& 1\right.$, where $l_{b}$ is the beam raduss) the fields extend a skin depth 1ndependent of the betim sizc

For a laser diver $\left(n_{b}=0\right)$ in the linter regime, the fields are given by [13]

$$
E / E_{0}=-\int d t^{\prime} \sin \left[\omega_{p}\left(t-t^{\prime}\right)\right] \vec{\nabla} a^{2}\left(r^{\prime}\right) / 2
$$

The radial extent of the fields driven by a laser is on the order of the itansverse laser intersity ptohle, I t , the laser spot size Transversely, the laser ponderomotive force is detemined by the local gradient in laser intensity, whereas the fields of a nurrow beam driver always extend a plasma skin depth As discussed below, this fact has consequences If shapitig the transwerse fields (controlling the focusitig forces) are required

It is destrable to have independenl control over the accelerating and focusing fortes in an accelerator, 1 , one would like to independently tuse the focusing forces for matched beart propagation For glven normalızed emittance $\varepsilon_{\mu}$ and beam energy $\gamma_{b}$, the matched spot size of the beam is $r_{\alpha}=\left(\varepsilon_{\alpha} / k_{\beta} \gamma_{b}\right)$ I/ ${ }^{2}$, where $k_{\beta}$ is determined by the focusing force $F_{1} /\left(m^{2} c^{2}\right)=-k_{j}^{2} r$ For a laser driver, the Iranswerse foelasing force us determinted, from $E q$ (d), by the local transwerse gradient of the lasser untensily $F_{\mathrm{r}}$ te $\partial_{1} a^{2}$ Hence, by shapung the transwerse laser intensity profile, the amplitude of the focusing force can be controlled In pracuce this may be done by combuning higher order laser moxles (which can alt be gulded in a parabolic plasma channel) [ ]4]

Sunce the self-fields of the beam exiend a plasma skı depth, to shape the teansverse fields in a beam-driven plasma wave requires using a broad beam such that ihe beam radius is many skin depths $k_{p} r_{b} \gg$ I In this sibuatıon, the return current passes through the drive beam, and, hence, the beam is subject to filamentation instahility [I2] Tempora] growth rates for the beam filamentation insiabilıty are glven in Ref [15]

Most present experiments in beam-driven or Jaser-driven plasma accelerulog do nor operate in the linear regıme, but in a highly-nonlinear regime. This nomlinear regime is characterized by expulsion of plasma electrons from behind the driver and formation of a co-moving cavity This regime was fitst analyzed by Rostrizweig ef al [16] for beam 

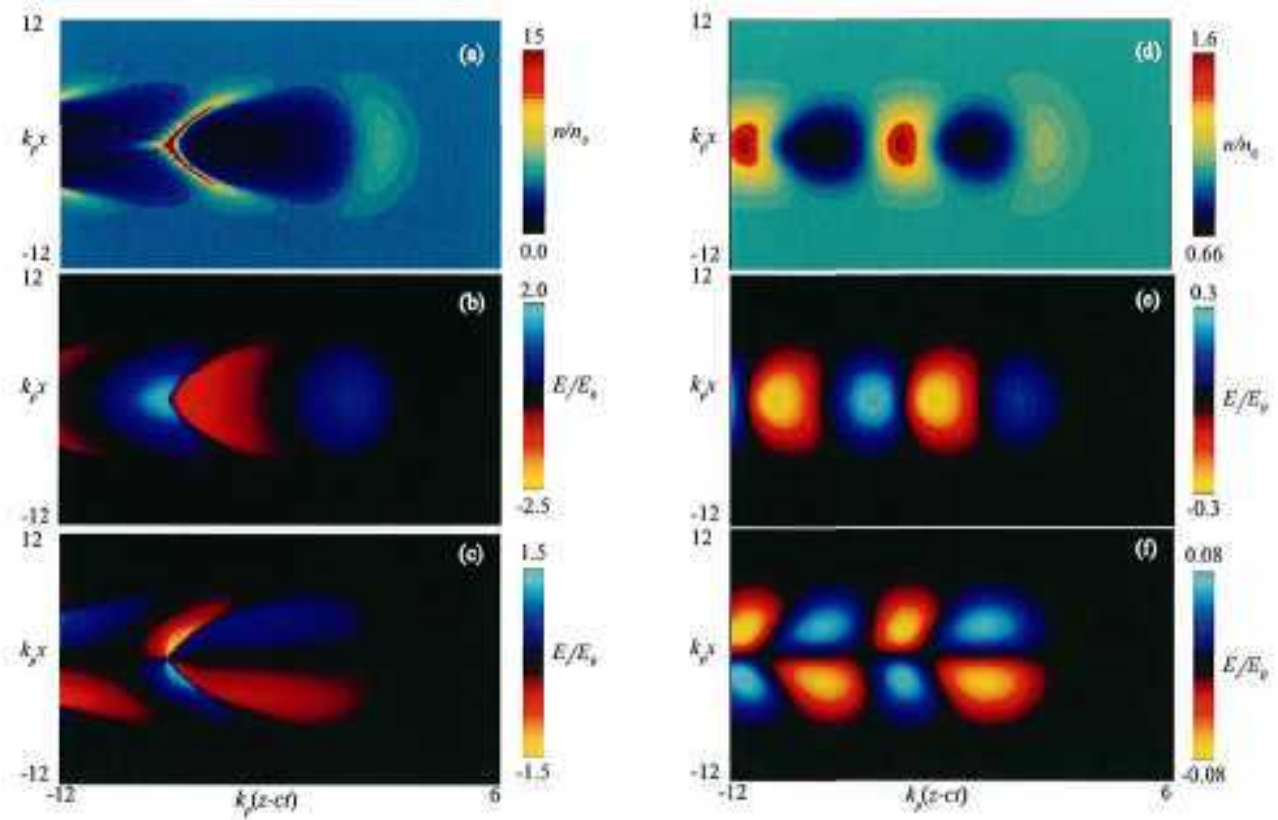

FIGURE 1. Left: Plasma wave excitation in the nonlinear regime: (a) electron density $n / n_{0}$, (b) axial electric field $E_{2} / E_{0}$, (c) transverse electric field $E_{r} / E_{0}$. Laser with $a_{0}=3.5, k_{\rho} r_{0}=5$, and $k_{p} L=1$ is propagating to the right [centered at $k_{p}(z-c t)=0$ ]. Positron acceleration and focusing only possible in electron density spike at back of the cavity $k_{p}(z-c) \simeq-6$. Right: Plasma wave excitation in the quasi-linear regime: (d) electron density $n / n_{0}$, (e) axial electric ficld $E_{z} / E_{0}$, (f) transverse electric field $E_{r} / E_{0}$. Laser with $a_{0}=1, k_{p} r_{0}=5$, and $k_{p} L=1$ is propagating to the right [centered at $k_{p}(z-a)=0$ ]. Nearly symmetric regions of focusing and acceleration for both electrons and positrons in quasi-linear regime. Numerical modeling shown in (a)-(f) performed using INF\&RNO [19],

drivers. This nonlinear regime has several attractive features for electron acceleration. In particular, in the cavity, the focusing forces are linear (determined by the ion density) $\left(E_{\gamma}-B_{\theta}\right) / E_{0}=k_{p} r / 2$, and the accelerating forces are transversely uniform $E_{z} / E_{0}=k_{p} \zeta / 2$. The condition for cavity formation, referred to as the blow-out regime, is that the beam density be greater than the plasma density $n_{b}>n_{0}$, the beam dimensions be less than a skin depth $k_{p} r_{b}<1$ and $k_{p} L<1$.

It was later discussed $[17,18]$ that this cavitated regime can also be accessed with a laser-driver, and for laser drivers is referred to as the bubble regime. The condition to enter this regime using a laser driver is that the nonlinear ponderomotive force balance the space-charge force of the bare ions $k_{p}^{-2} \nabla_{\perp}^{2}\left(1+a^{2}\right)^{1 / 2} \sim n / n_{0}-1$, or, for a Gaussian pulse profile, $a^{2} /\left(1+a^{2}\right)^{1 / 2} \sim k_{p}^{2} r_{0}^{2} / 4$. Therefore, for laser-drivers, by increasing the laser intensity, the nonlinear bubble regime can be accessed. Note that one can also enter this regime by using a sufficiently tight laser focus to produce a large transyerse ponderomotive force. Figure $1(\mathrm{a})$-(c) shows a laser-plasma accelerator entering the bubble regime. As the laser intensity increases, the regions of focusing and defocusing of electrons become highly asymmetric. This is shown in Fig. I(c). This asymmetry in the wake may be an issue if acceleration of positrons are desired for high energy physics applications. Positrons can be accelerated and focused on the electron density spike at the back of the cavity [cf. Fig. 1(a)], where the attractive properties of the nonlinear bubble regime are lost. As the plasma wave becomes more nonlinear, the phase region where positron acceleration and focusing is possible becomes narrower.

By reducing the laser intensity, the laser-plasma accelerator enters the guasi-linear regime, as shown in Fig. I(d)(f). In the quasi-linear regime the fields are nearly symmetric for electrons and positron acceleration and focusing. In addition there is no self-trapping, stable laser propagation can be achieved in a plasma channel, and the transverse focusing fores can be controlled via the transverse laser intensity profile as discussed above.

Accessing the linear regime of beam-driven plasma accelerators (to facilitate positron acceleration) requires $E_{z} / E_{0} \lesssim 1$. Assuming a bi-Gaussian electron beam with $k_{p} r_{b} \& 1$, the solution to Eq. (2) is $E_{z} / E_{0} \approx \sqrt{2 \pi}\left(n_{b} / n_{0}\right)\left(k_{p} L\right) \exp \left(-k_{p}^{2} L^{2} / 2\right)\left(k_{p} r_{b}\right)^{2} \ln \left(1 / k_{p} r_{b}\right) \propto N_{b} n^{1 / 2}$. Hence operating in the linear regime re- 
quires low plasma density or low beam charge For fixed bunch charge ( 1 e , fixed druer energy to be transferred to a witmess bunch), operatıng in the linear regıme xequires low plasma densilies L.ower plasma densitıes result in smaller

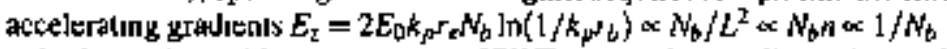

In the nonlinear blow out regume of PWFA, partıc]e-1л-cell simulations have shown [20] that the lincar beam leлgth scalung for the acceleratıng gradıen holds in the nonlınear regime, namely $E_{2} \propto N_{b} / L^{2} \propto N_{b}$ t, assuming the resonamt condition $k_{p} L \approx \sqrt{2}$ ( $\in$ e, optimizing the beam lengih) The operahonal density in the non] inear blow-out regime is determuned sumply by the ayaslabulity of short dive bunches, and the size of the acceleraing field is proportional to the plasma densıly For example, given a $30 \mathrm{\mu m}$ beem length, indicates one should operake at $\sim 10^{17} \mathrm{~cm}^{3}$ to maximaze the acceleratting gradient

The energy gain in a beam-driven plasma wave is given by the transformer ratio $R=\Delta \gamma / \gamma$ trwe, where $\Delta \gamma$ is the energy ganed by an electron at the peak of the accelerating field and $\gamma_{\text {tor }}$ is the energy in the drive bunch Under general considerations [21], $R \leq 2$ for plasma waves driven by symmetric beams Hıgher iransformer ratıos may be achewed by using asymmetnc beams to drive the wake In particular, transformer ratios wilh $R>2$ can be achieved using a long $\left(k_{p} L \geqslant 1\right)$, ramper beam (1 e , triangtlar bunch with bow density at the head), or, equivalently, a train of bunches with increasing charge $A$ higher trainstommer tatio enables a more compact accelerator val the use of lower energy dove beams (potentially produced from smaller conventional accelerators) Approptiately shaped ramped bunches have been produced experımentally [22). as wel] as ramped bunch trans [23] Experimeals using a ramped bunch train in a dielectric-loadod wake/ield accelerator have denonstrated high (ransformer ratios [24] One limtation with using long bearns for high tansformer tatros, is that long beams are subject to instabilines. and, un parucular, the electron-hose instabilicy $[25,26]$ The growth rale of the electron-hose instability scales as $\Gamma_{\text {hose }} \approx y_{s}^{-1 / 6}\left(a_{p}\right)^{1 / 3}\left(k_{p} L\right)^{2 / 3}$, indicatinf that the most cffectuve way to suppress hosing is to reduce the bunch length

In a laser plasma acoclerator, the energy gain 15 limsted by the laser energy depletion length The laser depletion length [2] ], for fixed laser intensily, scales as $L_{d} n^{-3 / 2}$ Since, for fixed intensly, the acceleralıng field of the plasma wave scales as $E_{z} \sim E_{0}=n^{1 / 2}$, the energy gajn in a single laser-plasma accelerator scales with plasma density as

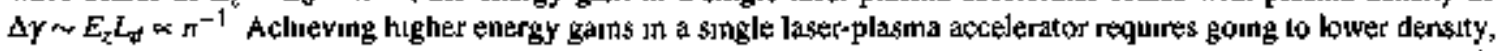
lower gradient, and longer interaction lengths Present laser-plasma acteleralor experiments typically rely an selftrapping of plasma electrons The self-Irapping threshold is determuned by the phase velocity of the plasma waye [28] In contrast to beam-driven plasma waves, the phase velocity of the laser-dnven plasma wave us a function of plasma density, and for fixed intensity, the Lorentz factor of the phase velocity scales as $\gamma_{p} \approx \omega_{0} / \omega_{p} \propto n 1 / 2$, where $a b=2 \pi c / \lambda_{0}$ is the laser frequency Hence, to achieve high cmergy gans requires operating at low plasma density, and, as a consequesce of the uncreased phase velocity, using some form of triggered injection Several methods of trigged ınjection are actively being explortod, such as colliding pulse injection [29, 301 , using plastma densıty gradietsts $[31,32]$, and conızation anjection [33-36]

\section{DRIYER PROPAGATION AND COUPLING}

Plasma-based accelerauon can be limited by the laser-plasma or beam-plasma inieracton length This interacion length may be set by etther the characterısic propagatson distance of the driver, or driver-plasma unstabilites For a beam-disyer, the charactenstic scele length for bearn evolution is the beta function $\beta=r_{b}^{2} / \varepsilon_{n}$, iver which the beam duverges In the nonlinear blow-out regime, the body of the beam may be self-guided in the cavity, but the head of the beam (outside the cavity) will contınue to diverge, leading to beam head erosion The rate of head erosion wil] be proportional to the beam emittence A straghtforward soluiton to extending the beam-plasma unteraction length is io use a low emitlance bean For example, using a beam with a geometre cmitunce of $\varepsilon_{1} / \gamma_{b}=1010$ m-rad and a $10 \mathrm{~km}$ beam radios, yields $\beta=1 \mathrm{~m}$

A tighdy focused laser diffracts, and the lengh byer wheh the laser diffracts is the Raylengh range $Z_{R}-\pi, \pi_{0}^{2} / \lambda_{0}$, Where $r_{0}$ is the laser spot suze and $\lambda_{0}$ is the laser wavelength In the nonlinear bubble tegirice, the body of the laser may be guided in the cavity, but the head of the laser will be outside the cavity and will contunue to diffract, leading to erosion of the liead of the laser The Raylejgh range is typkally the shortest length scale for laser evolution For example, $Z_{R}=2 \mathrm{~mm}$ for $\rho_{0}=25 \mu \mathrm{m}$ and $\lambda_{0}=1 \mu \mathrm{m}$ The gcometris emittance of the photon beam is fixed by the laber wavelength, and therefore some forn of external guidıng must be employed Preformed plasma densuly channels ( $1 \mathbf{e}$. talorıng the Iransverse plasma density profile such that there is a density minımum on axis) have been successfully demonstrated as an e[fect]ve mechanısm for guidıng a laser pulse [37-39] Hydrogen capil]ary drscharge waveguldes [40] have been used to generate long (few cm), low densily (few $10^{18} \mathrm{~cm}$ ) plasina channels suitable for producing 
high-energy beams in a laser-plasma accelerator $[3,41]$

The phase velocity of the plasma wave is approxımately cyual to the driver propagaluun velocily The velocity of the heam driver is typically ultoa-re[atıvisbc, $c g, b_{b}=\gamma_{\rho} \sim 10^{4}$ These large pliase velocitics have several adyantages no trapping of background plasma electrons (dark current free), negligible silupage belween the druve and a wilness bunch, and reduction of heam-plasma instabilitles (I e , a stiff driver) For laster-driven plasma waves the phase velocily is rather low The laser dnver propesgation velocity is apptoxirtate the driver velocily, and using $\lambda_{0}=1 \mu \mathrm{m}$ wavelength In 1ypucial plassna dentulues $n \sim 10^{17}-10^{19} \mathrm{~cm}^{-3}$, y $\approx \gamma_{0} \sim 10$ - 100 This relatively low plasma waye phase velocity can allow trapping of background plasma electrons as discusscd in the previous section The low phese velocily also resulis in slippage between the plasma wave and the beam The distance over which the beam slips from an accelerating to a deceleration region of the plasmn wave, or dephasıng lenght, ts $L_{d p \sqrt{s}} \sim \lambda_{p} \gamma_{p}^{2}$ Thıs slappage may limit the energy gain $\Delta \gamma \propto \gamma_{g}^{2}$ One solution to s] lppage is to taper the p]asma density longitidunal]y $[42,43], 1 e$, on the scale of the dephasing length, slowly increase the plasma density, thereby decreasing the plasma wayelength $\lambda_{p} \propto \pi^{-1 / 2}$ and mantaising the phase of the beam in the plasma wave By tallojing the plasma both transversely (for laset gujding) and longitudinally (for beam-wake phase-locking) both diffracuion and dephasing may be overcome in this case the sinyle stage encrgy gain $\mathrm{u}$ a laser-plasina accelerator is limuled by laser energy depletion

For fixed driyer cnergy, increasing the beam energy requires staging plasma arccelerators The total size of the accelerator will be determined not anly by the leagth of the plasma accelerator, but also by the distance to couple a new diver unto subsequest plassna aceeleritor stages Consider an accelerator slage consishng of the plasma lengih and the driver-coupling distance $L_{\text {alace }}=L_{\text {complot }}+L_{\text {plesend }}$ The total length of the accelerator will be $L_{\text {conal }}=$

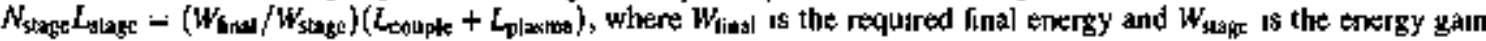
per stage (approxumately the druver energy) Minımızing the accelerator length and maxımızing the geometric gradient requires $L_{\text {coopt }} \sim L_{\text {plaurs }}$ For example, coupling a $\sim 25 \mathrm{GeV}$ beam unto a plasms whıle preserving beam qualıy, requres $\sim 100 \mathrm{~m}$ Compling tens of J of laset energy, while avoiding demage to optıcs, requites several theter's using conventional focusing optics A laser-dnver may a]so be in-coupled using a plasme mirtor [44, 45] A plasma mirror uses an overcntucal plasma created on the surface of a renewable matersal (tape or inguid jet) by the foot of an untense laser pulse to reflect the body of the laser pulse Using a plasma muror, laser-driver in-coupling may be achieved in $\lesssim 10 \mathrm{~cm}$ Usung laser-drivers offers the potential of ultrahigh average or geometric gradients of the staged plasma accelerator $[9,10]$

Note that given a driver of sufficsent energy coupling additional drivers would be upnecessary For example, in the case of a high-energy beam-drwen accelerator, a proton beam could acceletaled to TeV energes in a conventionat circular acceletator, and used lo drive a plasma wave, trantferring a latge frachon of ats energy to a plasma wawe in a sing] stage [46]

In the case of a laser-dnven plasme accelerator, even whth a suffic wently high energy laser druver, staging is desirable to maintain high aceekeratıng gradienl As discussed above, obtajning high crergy in a singke laser-plusma acceleralor reguires operating at low plasma densily $W_{\text {appe }} \approx 1 / n$, with longer plasmas $L_{\text {plasm }} \approx m^{3 / 2}$ and lower accelerating gradients $E_{q}$ os $t^{\mathrm{J} / 2}$ A more compact accelerator design (with highęt average gradrent) would use multuple highdensity, u]trahigh gradient ]aser-p]asma acceletrator stages [10]

\section{SUMMARY AND CONCLUSIONS}

In this proceedugs paper we have discussed some of the similarities and differences between plasma acceleration alsung laser drıvers or particle bean drivers Although laser-dnven and beam-driven plasma acceleration are equivalenı in some aspects, there are some fundamental diferetces that atise from the physics of the excjtarion mechanisms For the case of the laser-druvers, excitalion 15 from the nonlinear ponderomolive force, and for beam-drivers, the spacecharge force The different physical mechanisms, as well as the typical characteristics of the drivers, have important implications for the design of plasma-besed accelerators

The field structure of the plasma wave can he strongly dependenl on the driver For example, in the lineris regime, the fields of u tightly focused electron beam extend al least a plasma skin depth, independent of the transverse bunch strocture, and therefore shaping the transverse fields by shaping the drive bujich is problematic In contrast, the transverse fields of the laser-dnven plasma wave are determined by the locel transverse gradient in laser untensity, and therefore the isansverse fields (and the focusing forcs) can be controlked by controllung the transyerse laser intensity profile

The nonlıear cavitated regume can be accessed by euther a beam dinver or a laver druver In this regime the phase 
regron where positron acceleration is possible is greatly reduced For beain-drivers of fixed charge, operating in the luneat Iegirne tequutes using low density (and consequently low accelerating gradjent) The acceleraturg gradıent of the beam-druven plasena waye scales as $E_{2}$ or $1 / L^{2}$, and, herice, the operational density is detercmined by the avallabiluty of short parkcle beams The operation density for laser-driven plasma waves is determined by the laser pulse energy and laser depietuon length

In practice the phase velocity of the beam driven plasma wave as typecally much lacter then the phase velocity of the laser-dnven wave $\gamma_{i} \& \gamma_{g}$ One consequence is the potenttal for self-trapping of background plasma electrons in laserdnven plasma accelerators Another consequence is sluppage between a relatıvistuc wimess beam and a laser-drven plasma wave This shppage can limit the energy gain, and plasma tapering may be used to overcome this immrtation

In this paper, we haye discussed PWFAs driven by electron beams Plasma wayes may aliso be excited by posilrons, where the dnver atıracts electrons in an inilally neutral plasma creating a space-charge oscillahon [47] Proton beams are also being actively considered for plesma wave excitiotion [46] The challenge for proton beam drivers is gerterating short (on the order of the plasma period) proton beams to resonently excite large plasma waves PWFAs drven by cleciron beans have recejved the mosl attention because of the avalabilty of high average and peak power electron beams for druvers

Mininjzing the dnver coupling length is atso essential to staged plasma acceletator design In a multı-stage plasma acceleralor the sıze of the machine (and the ayeragetgeometre gradient) will be determined by the distance to coniple a fresh drwer into subsequent shges Lasers offer the possibslaty of short coupling distances, commensurate with the plasma length, enablung ultca-hugh aycrage/geonetric gradrents for the multu-stage plasma accelerator

In this paper we have also focused on accelerator properties ansing from plasma physieg, nad not addressed the dnver technology It should be noted that hıgh-power, high efficiency. high repetition rate charged particle beams are presently avalsble from conventional accelerator systems The tootprint of such a conventionol accelerator system (e $\mathrm{g}$, using S.band linacs) is large The footpnit may be reduced, for example, by using X-band technology to accelerate the drive beams and beam shaping to yield a high transformer ratıo Signuficant $R \& D$ is required to realize high transformer tatios $(R>2)$ wilh slable bcam propagation in bcam-driven plastna acceleralurs

PTesently, the laser technology exists to deliver intenste, short laset pulses, eg, tens of J of laser energy in tens of fs (1 e, PW peak power laser systems), operating at I- $10 \mathrm{~Hz}$ Such a PW laser systern occupies a small footprint ( $<10 \mathrm{~m} \times 10 \mathrm{~m}$ in area), and is capable of delıvering electron beams with energes up to 10 GeV High average power and high-efircierky lasers are under deyelopment, and laser systems usung diode-pumpexl ceramucs show promuse for greatly increasing the efficiency and awerage power of short-pu]se laser sysiems [48]

Several new acceleralor experimental faci]jies are under constructuon worldwide to explore the physics of these excitation mechanusms and io develop plasma accelerators Two such facilites, BELLA (Berkeley I ab haser Accelerator) [49| and FACET (Facililes for Accelerator science and Experimental Tesi beams al SLAC) [50] here been reported at this workshop and show great promise loward adyaneing the development of plasma accelerators

\section{ACKNOWLEDGMENTS}

This work was supported by the Director, Office of Science, Officc of High Energy Physics, of the $U \mathrm{~S}$ Department of Energy under Contract $\mathrm{No}$ DE-AC02-05CHII23I

\section{REFERENCES}

1 T Tajuma, and I M Dawson, Plyss Rev Lert 43, 267-270 (1979)

2 E Esarey, C B Sthrecter, and W P Leemans, Rev Mort Phys 81, 1229-1285 (2009)

3 C E Clayton, K A Mash, A Dyson, M Everet, A Lal, W P Leemans, R Willams, and C Joshi, Phys Rev Letr 70, $37-40(1993)$

4 D Stnckland, and G Mournu, Opt Commin 56,219 (1985)

5 P Chen, J M Daw5on, R W Huff, and T Kalschleas. Phys Rev Lett \$4, 693-696 (1985)

6 J B Rosenzwelg. Phys Rev A 38, 3634-3642 (1988)

7 W P Leemans, B Nagter, A I Gonsalves, C Toth, K Nakumura, C O R Goddes. E Ecsiry, C B Schroeder, and S M Hooker, Nathre Plys 2, 696-699 (2006)

8 I Blumeufeld, C E Clayton, F-J Decket, M I Hogan, C Huang, R Ischebeck, R Iserson, C Joski, T Katsouleas, N Knby, W Lu, K A Mursh, W B Morı, P Mugglı, E Oz, R II Suemánn, D Walx, and M Zhou, Nature 445, 741-744 (2007)

9 W Lemans, and E Esarey, Physirs Todtas 62, 44-49 (2009) 


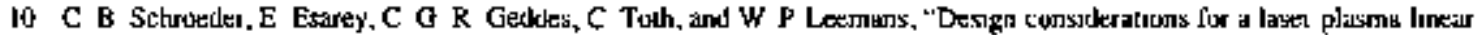
collider," in Advarted Accelerator Concepts, ediled by $C$ B Schroeder, E Esaley, and W Leeman5, AIP, New York, 2009, wit 1086. pp 208-214

II A Seryi, M I Hogan, S Per,T O Raubenhesmer, P Tenenbaum, C Huang, C Joshı, W Mon, T Kalsateas, and P Mugg].

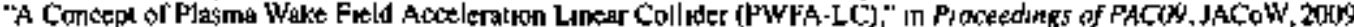

12 R. Kemigs, and B E Joncs, Phys Flaids 30, 252263 (1987)

13 P Sprangle, E Esarey, A Ting, and G Joyce, Appt Phys Lets 59, 2146-2148 ( 1988 )

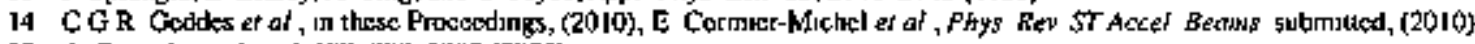

15 A Brek, Astiophys of 6yy, 940 ] 10013 (2009)

16 J B Rosenzwesg, B Brezznaj, T Katsoukas, and I I Su, Phys Rev A 44, R6189-R6192 (1991)

17 P Morra, and T M Anlonsen, J1, Phys Kev E \$3, R2069-R207I (1996)

$1 B$ A Pukhoy, alsd I Meyer les Vehn, Apy' Phys B 74,355-361 (2002)

19 C Benedett et at , in these Procetedings, (2010)

20] W Lw, C Huang, M Zhow, W B Mon, and T Katsouless, Pitys Plasmas 12, 063101 (2005)

21 R D Rulh, A W Chao, P L Morton, and P B W]lson, Patt Acce' 17.171-189 (19B5)

22 R J England. I B Roserizweıg, and G Trawsth, Pliys Rev Lett 100, 214802 (2008)

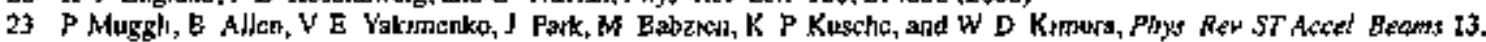
$052303(2 \mathrm{~F}] 0)$

24 C Jing, A Kenarcyken, I G Power, M Conde, Z Yusof, P Schocssow, and W Ga, Pipys Rev Lell 98, 144801 (2007)

25. A A Geracl, and D H Whittum, Phys Ploswas 7, 343] (20) (O)

26 C Huàng, W Lu, M Z Zrou, C E Clayton, C Josho, W B Morı, P Muggh, 5 Deng, E Oz, T Kalsouleas, M J Hogan, I Hlumen[e]d, F J Decker, R J sethebeck, R H Iversom, N A Kurby, and D Walz, Phys Rev /els 99, 255001 (2007)

27 B A Shadwick, C B Schroeder, 㔭 E Esarey, Phys Plasnkcy I6, 0.56704 (2009)

28 C B Schroeder, E Esarey, B A Shadurck, and W P Leemans, Phys Plastnas 13,033103 (2006)

29 E Esarey, R F Hubbard, W P Letrins, A Ting, and P Sprangle, Phys Rev Lett 79, 2682-2685 (1997)

3) J Faure, C Rechatın, A Norlm, A Lrfschilz, Y Gilnec, and V Malka, Natwe 444, 737-739 (2006)

3] S Bulanov, N Naumova, F Pegoraro, and I Sakat, Phys Rer E 58, R5257-RS260 (I998)

32 C G R Geddes, K Nakemurn, G R Plateau, Cs Talh, E Cormıer-Mıched, E Esarey, C B Schuroder, J R Cary, and W P Letomans. Phys Rev Lett 100, ZISTO04 (201013)

33 M Clen, Z -M Sheng, Y-Y Ma, and J Zthang, J App' Phys 99,056]09 (2006)

34 A Pak, X A Marsh, S F Martins, W Lu, W B Morı, and C Jochs, Phys Rev Lell 104, 025003 (2010)

35 C MeGuffey, A G R Thomes, W Schuinakcr, T Matsuoke, V Chrykor, F J Doller, G Kalınachenko, V Yanowsky, A Maksimchuk, K Krushelnck, V Y Bychenkow, I V GlazyrIn, and A V Karpeev, Phys Rev Left 104, 025004 (2010) 36. M Chen at at, in these Proceedings, (2010)

37 C. G Dufee III. and H M Mulchberg, Phys Rev Lett $71,2409-2411$ (1993)

$38 \mathrm{P}$ Wollown, E Esarey, and W Leemans, Phys Plasthers 6, 2269-2277 (1999)

39 C 0 R Geddes, C Toth, J vau Tlborg, E Esarey, C B Schroeder, I Cary, and W P Leemarts, Phys Rev Lett 95, 145002 (2005)

40 S M Hooker, D J Spence, and R A Smuth, J Opt Soc Am B 17,90.98 (2000)

41 K Nakamura, B Nagler, C Toth, C $\mathbf{G}$ R Geddes, C B Scturoeder, E Eserey, W P Leemans, A J Gonsulwes, and S M Hooker, Phys Plasmas 14,056708 (2007)

42 T Kalsowieas, Phys Rev A 33, 2056-2064 (1986)

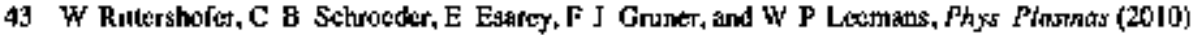

44 D Pantesenkn et at, $f$ Appt Phys (2010)

$45 \mathrm{~T}$ Sokollok et at , $m$ these Procecdings, (2010)

46 A Caldwell, K Lolow, A Pukhov, and F Stmon, Natitre Plys 5, 363-367 (2009)

47 B E Blue, C E Clayton, C L O'Conned, F J Dosker, M J Hogan, C Huang, R Iverson, C Josh, $T$ C Kalsouleas, W Lu, K A Marsh, W E Mars, P Muggit, R Sremann, and D Wald, Phys Rev Left 90, 214801 (2003)

48 A lkesue, and Y L Ausle, Netwe Phoronses 2, 721-727 (2008)

49 W P Learnans et at , in these Proceedugs, (20]0)

$50 \mathrm{M} J$ Hogan at af , in these Proceedings, (20 to) 


\section{DISCLAIMER}

This document was prepared as an account of work sponsored by the United States Government. While this document is believed to contain correct information, neither the United States Government nor any agency thereot, nor The Regents of the University of California, nor any of their employees, makes any warranty, express or implied, or assumes any legal responsibility for the accuracy, completeness, or usefulness of any information, apparatus, product or process disclosed, or represents that its use would not infringe privately owned rights. Reference herein to any specific commercial product, process, or service by its trade name, trademark, manufacturer, or otherwise, does not necessarily constitute or imply its endorsement, recommendation, or favoring by the United States Government or any agency thereof, or The Regents of the University of California. The views and opinions of authors expressed herein do not necessarily state or reflect those of the United States Government or any agency thereof or The Regents of the University of California. 